Theories \& Applications, the International Edition

Printed Version : (ISSN 2090-5262)

Online Version : (ISSN 2090-5270)

July 2014, Volume 4, No. 2 Pages (39 - 50)

\title{
Expertise Systems and Decisions Support Systems as an Access for Decision-making in Egyptian Sport Institutions.
}

Raafat Said Hendawei

Lecturer at the Department of Sport Management and Recreation, Faculty of Physical Education for Men, Alexandria University, Egypt.

\section{Hossam Hassan Shehata}

PhD from Department of Sport Management and Recreation, Faculty of Physical Education for Men, Alexandria University, Egypt.

\begin{abstract}
Sport institutions face several subsequent ideological and technological changes whereas the role of information systems in these institutions is restricted on storing historical information only to go back to them in similar cases. With sport institutions management conflict to rely on Decisions Support Systems (DSS) or the Expert Systems (ES) is imperative that the development of Decisions making Systems in the least degree of insurance and risk to achieve the ideal use and distribution for resources and strategic planning of different sport projects. The study aimed at recognizing the role of expert systems as the most prominent superficial intelligence technicalities and DSS as the prominent information systems technicalities as an access for decision making at Egyptian sport institutions. The study was applied in a random sample of (50) information systems experts and sport management from members of general Assembly and Boards of directors in some sport institutions. The study results revealed a frame to determine the requirements of building and applying the ES, ESS and the mechanics of using them on the decisions level (strategically, tactical and executively) in the sport institution, as well as supporting for processes of (production, marketing, funding, Human Recourse) through providing information to select alternatives and suggest solutions for problems in which the institutions.
\end{abstract}

Key words: Decision Support Systems, Expert Systems, Sport Institutions, Decision-making

Introduction:

port institutions face several subsequent and influential ideological and technological changes on its strategic goals, that necessitates providing mangers with information in a form enabling them to use it proficiently to lake the best decisions with the least extent of uncertainty and risks and to achieve the ideal use and distribution for prevailing resources and strategic planning for different sport projects and activities.

Studies results of " Grzegorz, Domino (2011) (16), Moustafa Habshy (2008) (9),Rogulj, plestina(2006)(18), indicate that sport institutions management follows conventional systems in decisions taking, and the use of modern technicalities and equipments are restricted on keeping and printing, despite its availability and newness, lack of leaders specialized in managing sport information systems leading increase management problems, solidity of organization bodies and it's inappropriateness for systems, information technicalities and communication systems past experience management leaders objection for radical changes, the appearance of economy global and information technology, the rarity of resources and data exaggeration, increasing the competition severity that became a threat for local sport institutions as well as conflicting the existence of any form for expertise systems to support decision in sport institutions .
Each management level requires taking a decision, even if it is not supported with right and full information, this leads to a wrong decision, consequently the management work doesn't achieve the desired goals.

With the agreement of studies recommendations of Russell, et al. (2012), Srhoj, Cavala (2010) (21), Bai, Chen (2008)(12), Bhargava, Power, Sun (2007) (14), Bartlett (2006) (13), kim, Song, Hong (2005) (17) Simic, Devedzic (2003)(22), Wagner, Najdawi (2003) (23), Shimetal. (2002) (20), Dezman, Dizdar (2001)(15) on the importance of management information systems role in general and systems of supporting decision particularly in supporting decisions-making, definiteness of introducing the ES as one of the most important artificial intelligence and as an effective method in solving the problems pertaining specialized fields of sport management by in developing methods and systems to meet the urgent needs of the Director of information and empowers him to interact with the computer to make strategic and operating decisions. Here comes the question: How do the ES \& DSS support decision makers in sport institutions? So, both the researchers see the definiteness of studying the ES and decision support system as an access for decision making in sport decisions. 


\section{Aims of the study:}

Recognizing the ES \& DSS as an access for decision making in sport institutions

Question of the study:

The nature of the exploratory study imposes its hypotheses formulation about the identity of the following:

1. What is the reality of the ES and decision support system in Egyptian sport institutions?

2. What are the requirements of DSS as an access for decision making in Egyptian sport institutions?

3. What are the requirements of the ES as an access for decision making in Egyptian sport institutions?

4. What is the role of the ES \& DSS as an access for decision making in Egyptian sport institutions?

Terms of the study:

- Decision support systems in sport institutions(DSS):They are informational systems based upon using the computer where individual's mental abilities are integrated with computer's abilities in using information and patterns in purpose of improving effectiveness, quality and competency of decision and supporting management decisions makers ( no or semi structure ) in sport institutions ( procedural definition ).

- $\quad$ Expert systems in sport management( ES ):They are computer programs based upon the knowledge base derived from the experts and are able on derivation, inference, conclusion and interpreting decision making and can provide solutions of specific experience for management problems (unstructured - semi structured) in sport institutions (procedural definition)

\section{Procedures of the study:}

Method of the study: the descriptive method (survey method).

Temporal field: the study was conducted from 15/2$30 / 3 / 2013$

Spatial field: clubs and sport union according to membership size, activities - budget - space according to the study requirements.

Sample of the study: it included three management levels in sport institutions selected with class random method where total of study sample members (50) whose the conditions of scientific and practical experience are applied on them this is what table (1) shows.

Table (1)

Categorizing the study sample according to the management levels in sport institutions

\begin{tabular}{|c|c|c|c|c|c|c|c|}
\hline \multirow[b]{2}{*}{ Management levels } & \multicolumn{3}{|c|}{ Sport clubs } & \multicolumn{3}{|c|}{ Sport Federation } & \multirow[b]{2}{*}{ Total sum } \\
\hline & $\sum_{\text {工 }}$ & 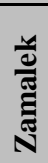 & $\frac{\pi}{80}$ & 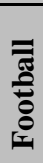 & 晜 & 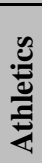 & \\
\hline 1- members of the general Assembly & 3 & 2 & 4 & 3 & 2 & 2 & 16 \\
\hline 2- members of board councils & 3 & 3 & 3 & 3 & 4 & 3 & 19 \\
\hline 3- information systems officials & 3 & 1 & 2 & 3 & 3 & 3 & 15 \\
\hline Sum & 9 & 6 & 9 & 9 & 9 & 8 & (50) \\
\hline
\end{tabular}

\section{Tools of data collection}

Questionnaire with comparison was used as a primary instrument to collect data according to the study nature.

\section{The first pilot study (preparing the questionnaire):}

1- Determining the basic axes of the questionnaire after knowing the scientific references and the related studies, then derived the questionnaire axes and presented them on (10) experts of staff members at faculties of (physical education- commerce, systems and information) in some Egyptian universities (contain no.1), where the experts agreed with $100 \%$ that the questionnaire includes (4) . Table (2) determines the rate of each axis representation in the questionnaire. 
Table (2)

Expert's opinions in the rate of representing each axis in the study questionnaire

\begin{tabular}{|c|c|c|c|}
\hline serial & Axes & $\%$ & Order \\
\hline 1 & The reality of ES \& DSS in Egyptian sport institutions & 6.10 & 4 \\
\hline 2 & The requirements of DSS as an access for decision making in sport institution & 30.30 & 2 \\
\hline 3 & The requirements of ES as an access for decision making in sport institution & 21.20 & 3 \\
\hline 4 & The role of ES \& DSS as an access for decision making in sport institution & 42.40 & 1 \\
\hline
\end{tabular}

2- Putting the statements of each axis, clarity of its their opinions, any statement was not omitted, and the formulation, concept, and order logically was questionnaire form remained as the same in the considered by placing the statements before its belonging axis. They were presented on the experts preliminary form (contain no.2) according to the experts opinions. Table (3) shows the questionnaire (contain no.1) to show their opinions. In the light of categorization.

Table (3)

Categorizing the study questionnaire

\begin{tabular}{|c|c|c|}
\hline Serial & axes & statements \\
\hline 1 & The reality of ES \& DSS in Egyptian sport institutions & 5 \\
\hline 2 & The requirements of DSS as an access for decision making in sport institution & 10 \\
\hline 3 & The requirements of ES as an access for decision making in sport institution & 7 \\
\hline 4 & The role of ES \& DSS as an access for decision making in sport institution & 14 \\
\hline
\end{tabular}

The second pilot study (scientific coefficients of the questionnaire)

1. the questionnaire validity: Judges validity was found by presenting the questionnaire on the experts in the field of study (appendix) to survey their opinions after clarifying the aim of the questionnaire to confirm its validity, as well as the appropriateness of the statements that measure these axes with Likert method triple evaluation (agree somewhat - disagree) distributed in the order $(1,2,3)$. Both the researchers accepted the rate of $(70 \%)$ as a minimum for accepting (axes, statements) of the questionnaire as shown in table (4).

Reliability of the questionnaire: By using Alpha Cronbach coefficient, on a pilot study of (20) members of the study original population, but outside the study sample where reliability coefficients significant coefficients at (0.05) level indicating the reliability of the questionnaire form for the study as shown in table (4).

Table (4)

Coefficients of validity and reliability for the study questionnaire

\begin{tabular}{|c|c|c|c|c|c|c|c|c|c|}
\hline \multirow[b]{2}{*}{ axes } & \multicolumn{2}{|c|}{$\begin{array}{c}\text { Validity of } \\
\text { axes }\end{array}$} & \multicolumn{6}{|c|}{ Validity of questionnaire statements } & \multirow[b]{2}{*}{ 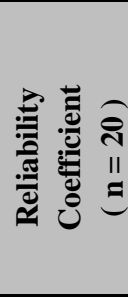 } \\
\hline & 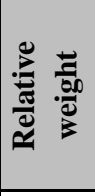 & $\partial^{\theta}$ & 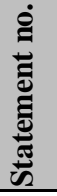 & 莺 & $\partial^{0}$ & 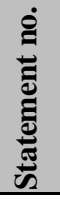 & 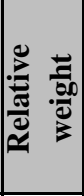 & $\partial^{0}$ & \\
\hline \multirow{3}{*}{$\begin{array}{l}1 \text { - The reality of ES \& DSS in Egyptian sport } \\
\text { institutions }\end{array}$} & \multirow{3}{*}{25} & \multirow{3}{*}{83.33} & 1 & 24 & 80 & 4 & 23 & 76.67 & \multirow{3}{*}{0.97} \\
\hline & & & 2 & 25 & 83.33 & 5 & 26 & 86.67 & \\
\hline & & & 3 & 27 & 90 & & & & \\
\hline \multirow{3}{*}{$\begin{array}{l}\text { 2- The requirements of DSS as an access for } \\
\text { decision making in sport institution }\end{array}$} & \multirow{3}{*}{29} & \multirow{3}{*}{96.67} & 1 & 29 & 87.88 & 6 & 27 & 81.82 & \multirow{3}{*}{0.93} \\
\hline & & & 2 & 32 & 96.97 & 7 & 26 & 78.79 & \\
\hline & & & 3 & 30 & 90.91 & 8 & 25 & 75.76 & \\
\hline
\end{tabular}




\begin{tabular}{|c|c|c|c|c|c|c|c|c|c|}
\hline & & & 4 & 31 & 93.94 & 9 & 28 & 84.85 & \\
\hline & & & 5 & 33 & 100 & 10 & 24 & 72.73 & \\
\hline \multirow{4}{*}{$\begin{array}{l}\text { 3- The requirements of ES as an access for } \\
\text { decision making in sport institution }\end{array}$} & \multirow{4}{*}{28} & \multirow{4}{*}{93.33} & 1 & 30 & 90.91 & 5 & 28 & 84.85 & \multirow{4}{*}{0.96} \\
\hline & & & 2 & 33 & 100 & 6 & 29 & 87.88 & \\
\hline & & & 3 & 31 & 93.94 & 7 & 26 & 78.79 & \\
\hline & & & 4 & 32 & 96.97 & & & & \\
\hline \multirow{7}{*}{$\begin{array}{c}4 \text { - The role of ES \& DSS as an access for decision } \\
\text { making in sport institution }\end{array}$} & \multirow{7}{*}{30} & \multirow{7}{*}{100} & 1 & 30 & 90.91 & 8 & 24 & 72.73 & \multirow{7}{*}{0.99} \\
\hline & & & 2 & 31 & 93.94 & 9 & 29 & 87.88 & \\
\hline & & & 3 & 33 & 100 & 10 & 25 & 75.76 & \\
\hline & & & 4 & 25 & 75.76 & 11 & 33 & 100 & \\
\hline & & & 5 & 29 & 87.88 & 12 & 26 & 78.79 & \\
\hline & & & 6 & 24 & 72.73 & 13 & 30 & 90.91 & \\
\hline & & & 7 & 26 & 78.79 & 14 & 31 & 93.94 & \\
\hline
\end{tabular}

The tabulated (r) value at free degree (18) and significance level $(0.005)=0.444$

It is shown from table (4) the rate of agreement for experts opinions in validity of the study questionnaire ranging between $(83.33: 100 \%)$, The rate of agreement on axes and statements of the questionnaire ranged between $(72.73: 100 \%)$ indicating the content validity of the questionnaire.

Presenting and discussing the results of the first axis:

Table (5)

Differences significance, percentages and order of the sample opinions in "The reality of ES \& DSS in Egyptian sport institutions $(\mathbf{n}=\mathbf{5 0})$
Presenting and discussing the results:

In relation with the nature of the study variables and to achieve its goal, both the researchers will present and discussing the results to respond the study questions in the light of the relative importance of the study axes as follows:

\begin{tabular}{|c|c|c|c|c|c|c|c|}
\hline \multirow[b]{2}{*}{ Statements } & \multicolumn{3}{|c|}{ Evaluation } & \multirow{2}{*}{ 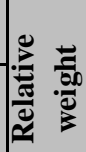 } & \multirow{2}{*}{$\stackrel{\sim}{\ddot{U}}$} & \multirow[b]{2}{*}{$\partial^{\ominus}$} & \multirow[b]{2}{*}{ రై } \\
\hline & 1 & 2 & 3 & & & & \\
\hline $\begin{array}{l}\text { 1. In the institution there is information systems and data bases to support } \\
\text { decision process on different management levels }\end{array}$ & 1 & 2 & 47 & 146 & 82.8 & 97.33 & 1 \\
\hline $\begin{array}{l}\text { 2. Decision makers in the institution rely on data base that information } \\
\text { systems provide }\end{array}$ & 45 & 3 & 2 & 57 & 72.27 & 38 & 3 \\
\hline 3. DSS provide different patterns for the raised problems & 44 & 3 & 3 & 59 & 67.23 & 39.33 & 2 \\
\hline 4. In the institution there are ES to support management decisions. & 49 & 1 & $\mathbf{0}$ & 51 & 94.1 & 34 & 4 \\
\hline 5. The institution provides experts and knowledge engineers for the ES & 50 & $\mathbf{0}$ & $\mathbf{0}$ & 50 & 99.98 & 33.33 & 5 \\
\hline
\end{tabular}

The tabulated (chi square ${ }^{2}$ ) value at freedom degree (2) and significance level $(0.05)=5.99$

It is shown from table (5) that there are significant differences between the real expected opinions for the study sample in all the statements of the first axis where the calculated values of $\mathrm{chi}^{2}$ ranged between (72.27: 99.98) They are all statistically significant, where the statement no. (1) achieved a relative importance of $(97.33 \%)$ whereas the relative importance of the sample opinions in the statements $(2,3,4$, and 5$)$ restricted $(33.33: 39.33 \%)$.
Both the researchers attribute this ( the status quo ) to the insistence of Egyptian sport institutions management not to exploit modern technicalities and equipments in supporting decision and is restricted on keeping and printing in spite of its availability and renewness by following the conventional methods in decision making, as well as the deficiency of competencies specialized in managing sport information systems, objection of previous experiences management leaders for not accepting these radical changes, exaggerating numbers of data, indicators and it's density lead to complication of institutional environment, as well as 
conflicting the existence of any form of ES in managing sport institutions or Knowledge bases supported with experts to computer, facilitating its use by decisions maker.

Presenting discussing the results of the second axis:
This accords with opinions of " Moustafa Habshy (2008)(9) Gamal Galal (2002)(11), Afaf Darwish (2009)(5), Yasser Nosear (2005)(11).

Table (6)

Differences significance, percentages, and order of the sample opinions in "the requirements of DSS as an access for decision making in sport institutions $(\mathbf{n}=\mathbf{5 0})$

\begin{tabular}{|c|c|c|c|c|c|c|c|}
\hline \multirow{2}{*}{ Statements } & \multicolumn{3}{|c|}{ evaluation } & \multirow{2}{*}{ 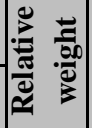 } & \multirow{2}{*}{$\ddot{U}$} & \multirow{2}{*}{ de } & \multirow{2}{*}{$\stackrel{0}{0}$} \\
\hline & 1 & 2 & 3 & & & & \\
\hline $\begin{array}{l}\text { 1. recognizing concepts and justifications of applying DSS in sport } \\
\text { institutions }\end{array}$ & $\mathbf{0}$ & 1 & 49 & 149 & 94.10 & 99.33 & 1 \\
\hline 2. Determining the design strategy for DSS in sport institutions & $\mathbf{0}$ & 4 & 46 & 146 & 77.90 & 97.33 & 2 \\
\hline $\begin{array}{l}\text { 3. Providing human potentials and resources specialized in managing } \\
\text { information systems and decision support }\end{array}$ & $\mathbf{0}$ & 8 & 42 & 142 & $\mathbf{5 9 . 6 7}$ & 94.67 & 4 \\
\hline 4. Forming a team of developing DSS in sport institutions & $\mathbf{0}$ & 11 & 39 & 139 & 48.51 & 92.67 & 5 \\
\hline $\begin{array}{l}\text { 5. Constructing DSS from the base of ( data - patterns - dialogue ) in sport } \\
\text { institutions }\end{array}$ & $\mathbf{0}$ & 7 & 43 & 143 & 63.87 & 95.33 & 3 \\
\hline 6. Selecting the appropriate mixture of DSS in sport institutions & $\mathbf{0}$ & 17 & 33 & 133 & 32.67 & 88.67 & 8 \\
\hline 7. Studying obstacles of DSS in sport institutions & $\mathbf{0}$ & 13 & 37 & 137 & 42.27 & 91.33 & 6 \\
\hline 8. Feedback of systems outputs as new access. & $\mathbf{0}$ & 25 & 25 & 125 & 25 & 83.33 & 10 \\
\hline $\begin{array}{l}\text { 9. Developing the legislative frame for managing information systems in } \\
\text { sport institutions. }\end{array}$ & $\mathbf{0}$ & 15 & 35 & 135 & 36.99 & 90 & 7 \\
\hline 10. Appointing security systems and information security in sport field. & $\mathbf{0}$ & 20 & 30 & 130 & 27.99 & 86.67 & 9 \\
\hline
\end{tabular}

The tabulated Chi ${ }^{2}$ at freedom degree (2) and significance level $(0.05)=5.99$

It is shown from table (6) that there are significant differences between the real - expected opinions for the study sample in all statements of the second axis where the calculated $\mathrm{chi}^{2}$ values ranged "25-94.10" and they are all statistically significant. The relative importance of the sample opinions ranged between (83.33:99.33\%).

Both the researchers attribute this to the consideration that decisions support systems are extension for management information systems to provide the necessary in formation for semi structured decisions making that management information systems don't provide. The system of decision support is called on a set of systems supporting the programming by collecting, storing, processing , broadcasting peer and digital in formation, constructing sketches patters, reports, communication and coordination between different activities in institutions saving time and ES of supporting management are multiple according to the circumstances of each sport institution. When a decision is maken, the influential situation in institution effectiveness should be studied and analyzed and that decision maker must aware of environmental factors and types of information available under the competitive circumstances. This accords with the opinions of both" Hassan EL shafaey (2010)(4), " Afaf Darwish " (2009) (5) , " Mohamed Salama , Samir Abdel Hamid" (2007) (8). Both the researchers see the difference between the design of decisions support system and the design of information system where it is characterized with synchronism because of none structured or semi structured nature of some decisions. So, managers rely on this system for its continuous change when needs change. The most important basic processes to design the system of supporting decisions in sport institutions according to the following stages:

- the stage of pre- design: by determining the desired goal of the system as a basis for all subsequent processes, determining available resources and specialized to design, manage and operate the system, determining the basic decisions by which the system of decision support provide to make the, and determining standard patterns that facilitate the task of providing the necessary information .

- Design stage: for the practical goals of the system through deciding what can be made of processes during real application of the system, designing an integration program between decision makers and the systems, designing information base that constitutes the heart of decisions support system, examining and testing the system by operating it experimentally to make sure of its success in achieving the determined goals. 
- Application stage: it focuses on preparing the appropriate climate to succeed the system application and make institutions managers make its credential and building the confidence with system potentials and its expected benefits.

- Assessment stage: it aims at recognizing the extent of achieving the determined goals for decisions support system in the frame of positives and negativities resulted in credential of the system applications. This process is accomplished through the existence of evaluation standards, the determining the achieved practical achievement. this process is a difficult one, but it is necessary to make sure the extent of the system benefit, preparing developmental plans to make the system performance raises to the level of standards, and in a way that motivates institution managers on their continuous credential for its applications according to Srhoj Cavala (2010)(21), Russell others (2012) (19) Ahmed El Kateeb, Khalid Zeaan (2009) (1). Both the researchers see the structural constitution of decision support system in sport institutions at the following sub systems:

- Sub system: contributes in achieving the task of discourse and dialogue between the beneficiary and the system and the language formation logical, procedural) including logical relations and the procedures to solve a specific problem and the beneficiary puts it, and the illogical - non procedural) language focusing on beneficiary definition of the problem and determining its properties only. Decisions support system selects the logical steps to provide the necessary information to solve the problem.

- The sub system of information base: constitutes the basis in decision support system by diagnosing the reality, analyzing the problems and determining the present and future opportunities, evaluation and guidance. During its design, accuracy, objectivity and inclusion of different aspects of activities must be put into consideration and consistency in terms of similarity of measurement concepts and its implications over the time allowing the field for follow up, and continuous updating for this base contents.

- The sub system for managing patterns: includes sport, financial and statistical models and by which information base can be functioned in the fields of prediction, modeling, and planning for activities in sport institution, supervising and evaluating it.
- The sub system for managing knowledge : dealing with semi typical and non-typical problems that need experience in dealing with it as well as the normal abilities present by controlling the support, The required experience is provided through the ES, the smart systems where experience is used and provided through " the knowledge base" Progress in the science of recognizing the speech indicates the potential of using the spoken mother tongue as the conversation language between the user and support system. The program of language processor (the conversation method) managing appropriateness and interaction with the rest of other three elements of the system (data management, patterns management, knowledge management). The previous mentioned accords with Alaa El Salmy (1999) (6), Dezman, Dizdar (2001) (15) opinions. Both the researchers confirm the importance of providing physical and human resources of information systems (such as final users and specialists in formation systems, computer physical resources, programming, data bases, mixed communication networks, a map of the system path), to receive data resources transferred them into information products, and inserting the concept of artificial intelligence and it's tools to make decisions through systems of managing information as systems of (operating coefficients, offices mechanic, the level of management information, supporting decision making, supporting team and administrative decisions, experience, artificial neural networks, mix support). This accords with Gasem Hamid (2011) (2), Moustafa Habshy (2008) (9) opinions.

The most important obstacles of DSS in Egyptian sport institutions are (technical) such as problems of design, data, cost and operation processes, organized ( legislative frame ) to exchange information between sport institutions and other (security, protecting data and information) with varied methods to assure privacy or reducing the negative effects as a result of penetrating it such as self-legal methods to protect intellectual ownership, consumer protection, legitimacy of contacts via internet , management and organization methods such as introducing the user, controlling devices and reaching data, methods of preventing information leak and reveal them to nonauthorized bodies, an integrated protection methods and assuring the content safety, methods of preventing denial, methods of follow up and control, as mentioned by Gamal Galal ( 2002) ( 3 ), Yasser Nousear ( 2005) (11). 
Presenting and discussing the results of the third axis:

Table (7)

Differences significance, percentages and order of the sample opinions in the "requirements of ES as an access for decision making in sport institutions" $(\mathbf{n}=\mathbf{5 0})$

\begin{tabular}{|c|c|c|c|c|c|c|c|}
\hline \multirow{2}{*}{ Statements } & \multicolumn{3}{|c|}{ evaluation } & \multirow{2}{*}{ 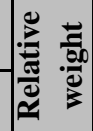 } & \multirow{2}{*}{ 苞 } & \multirow{2}{*}{ se } & \multirow{2}{*}{ 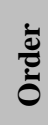 } \\
\hline & 1 & 2 & 3 & & & & \\
\hline $\begin{array}{l}\text { 1- Adopting the philosophy of artificial intelligence in management and } \\
\text { decisions taking in sport institutions }\end{array}$ & $\mathbf{0}$ & 11 & 39 & 139 & 48.51 & 92.67 & 4 \\
\hline 2- A use study of applying the ES in sport institutions & $\mathbf{0}$ & 3 & 47 & 147 & 83.06 & 98 & 1 \\
\hline $\begin{array}{l}\text { 3- Providing the human and physical resources that are appropriate for } \\
\text { using the artificial intelligence and ES }\end{array}$ & 0 & 7 & 43 & 143 & 63.87 & 95.33 & 3 \\
\hline $\begin{array}{l}\text { 4- Enriching knowledge base of ES with experts in managing sport } \\
\text { institutions and competence knowledge engineers. }\end{array}$ & $\mathbf{0}$ & 6 & 44 & 144 & 68.31 & 96.00 & 2 \\
\hline 5- Avoiding obstacles of using ES in sport institutions. & $\mathbf{0}$ & 16 & 34 & 134 & 34.71 & 89.33 & 6 \\
\hline $\begin{array}{l}\text { 6- Depicting organized structure of the artificial intelligence and ES in } \\
\text { sport institutions }\end{array}$ & 0 & 13 & 37 & 137 & 42.27 & 91.33 & 5 \\
\hline $\begin{array}{l}\text { 7- Newness and continuous development for the knowledge base of ES - } \\
\text { feedback }\end{array}$ & 0 & 19 & 31 & 131 & 29.31 & 87.33 & 7 \\
\hline
\end{tabular}

The tabulated $\mathrm{Chi}^{2}$ at freedom degree (2) and significance level $(0.05)=5.99$

It is shown from table (7) that there are significant differences between the actual and expected opinions of the study sample in all third axis statements, where the calculated $\mathrm{chi}^{2}$ values ranged "29.31:83.06". They are all statistically significant on behalf for the agreement of the statements maximum importance. The relative importance of the sample opinions is restricted between "87.33:98\%".

Both the researchers attribute this for considering the expert system one of the most prominent artificial intelligence technicalities and its application, as" programs consist of research knowledge bases and facts that can learn, acquire experience, simulate the behavior or thinking of the human expert in resolving a specific problem or finding a specific decision "where they were designed to help workers in different applied sciences such as sport management with its various branches, education, sport training, kinetics, bio mechanics and dealing with non-routine decisions that can't be predicted with its steps and other applications of artificial intelligence in different sport aspects such as processing natural languages, optical systems and automatic systems and programming, neural networks .

Both the researchers see that the ES is characterized with acquiring the knowledge and using it in reasoning , solving management problems efficiently and finding the relations between science of (perception - human knowledge computer) and connect it with the abilities by which the computer can perform better than the human such as digital calculations, storing data, frequent processes, whereas the human proceeds in intelligence, data perception, analyzing and understanding them, so artificial intelligence is connected with the concepts of symbolic processing as methods of logical inference, intuitive analysis for events and judge according to the experimental experience , patterns identical by analyzing different relations between events and processes to facilitate recognizing it's components (inference) as one concept of logical inference for the human mind to analyze and conclude the events , This accords with Bartlett opinion (2006)(13). Both the researchers summarize the structural constitution of the ES in sport institutions in integrated sets of sub systems that are:

- Knowledge base: it is an electronic bank for a set of facts, information, rules, laws and procedures that characterize the field of the problem and methods of representing knowledge including both facts and connect them logically. Knowledge engineer understands expert knowledge, derives and codes it in a program, so that he can represent knowledge in the expert system and store it at the knowledge base in the system according to several foundations, the most important of them are ( rules) and is the common method in representing knowledge ( if condition - Then - Action ) frames by organizing markers in classes based upon the common characteristics of relations rather than hierarchy order for facts ( cases ) such as previous performance, accidents and experiences (goals) where it is presented on the basis of a set of goals including data elements and it's stages . The expert system is developed by introducing additional knowledge. As problem develops by using the system of acquiring the sub knowledge. This accords with the opinions of Grzegorz, Domino (2011) (16), Rogulj, Papic, Plestina (2006) (18).

- Inference engine : it represents the intelligent ( processing ) part of the ES that interact with knowledge base where reasoning and perception are performed by using the base contents with a specific sequence, where it derives or deduces conclusions 
and resolutions related with the problem ( the research subject) through facts and specialized knowledge found on the knowledge base , drives ( the working memory ) new information and comparing them in purpose of concluding new facts through assessing if the condition is right or wrong by examining all rules, the examination process continues until the path is completed through all rules class. It can be more than one path to determine the value of the goal variable according to what Shim \&others (200) (20), Simic, Devedzic ( 2003 ) ( 22 ) mentioned .

- Both the researchers see that there is non-typical or exclusion inference engine for all types of ES, but it is designed according to a specific field of application. ( knowledge rules ) include also facts processed with specific rules and is programmed by the expert engineer for its dependence on inference from the knowledge bases and is specialized in a specific, whereas ( data bases ) contains data of daily processing's needing an analyzer systems designer issuing reports of sport institutions activities .

Presenting and discussing the fourth axis:
- User interface : the method of natural language relies on the interaction between the expert system and the beneficiary through natural conversation language

( the simplified conversation ) in terms of inference, interpretation , explanation, mechanic, the required flexibility to add new knowledge or make modifications during the development of problem solving . The beneficiary can raise questions to receive answers of the raised problem with formulation of inquiries, facts or conclusions or inferences and use the lists, pictures, figures, sounds and others.

- Both the researchers see that to overcome the hinders of applying the ES in sport institutions , they must be developed and provide varied skills and knowledge to the development team periodically beside the physical resources, so that the development process is executed in all its stages regarding the dynamics of building and developing the ES in different sport institutions, The previous mentioned accords with the opinions of Kim ,Son , , Hong (17) Nabil Moursy (2005)(10) .

Table (8)

Significance differences, percentages and order for the sample opinions in the role of ES and DSS as an access for decision making in sport institutions $(\mathrm{n}=\mathbf{5 0})$

\begin{tabular}{|c|c|c|c|c|c|c|c|}
\hline \multirow{2}{*}{ Statements } & \multicolumn{3}{|c|}{ Evaluation } & \multirow{2}{*}{ 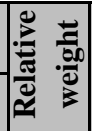 } & \multirow{2}{*}{ 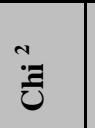 } & \multirow{2}{*}{$\partial^{\circ}$} & \multirow{2}{*}{ 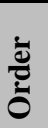 } \\
\hline & 1 & 2 & 3 & & & & \\
\hline \multicolumn{8}{|c|}{ The role of decisions support systems as an access for decision making in sport institutions } \\
\hline $\begin{array}{l}\text { 1- Improving the effectiveness of decisions taking as well as it's competency } \\
\text { through collecting data and complicated analysis patterns }\end{array}$ & $\mathbf{0}$ & 5 & 45 & 145 & 72.99 & 96.67 & 5 \\
\hline $\begin{array}{l}\text { 2- Helping managers in processes of their decisions taking for semi -and } \\
\text { non-structured - order activities }\end{array}$ & $\mathbf{0}$ & 2 & 48 & 148 & 88.46 & 98.67 & 2 \\
\hline $\begin{array}{l}\text { 3- Deep analysis for information by using (patterns - figures and maps } \\
\text { )and displaying them to be appropriate for the user }\end{array}$ & $\mathbf{0}$ & $\mathbf{0}$ & 50 & 150 & 99.98 & 100 & 1 \\
\hline $\begin{array}{l}\text { 4- Direct arrive for the descriptive data and the available amount in the } \\
\text { base of system data. }\end{array}$ & $\mathbf{0}$ & 14 & 36 & 136 & 39.51 & 90.67 & 11 \\
\hline $\begin{array}{l}\text { 5- The appropriateness of the used data for the circumstances of the } \\
\text { involved decision and the immediate answer on the individual answers. }\end{array}$ & $\mathbf{0}$ & 6 & 44 & 144 & 68.31 & 96 & 6 \\
\hline $\begin{array}{l}\text { 6- Confirming the relations and the comparative attitudes between } \\
\text { decisions variables that help in the process of solving the problem. }\end{array}$ & $\mathbf{0}$ & 13 & 37 & 137 & 42.27 & 91.33 & 10 \\
\hline $\begin{array}{l}\text { 7- Interacting with the system by using commands language allowing to } \\
\text { reach to the system and ask it directly }\end{array}$ & $\mathbf{0}$ & 11 & 39 & 139 & 48.51 & 92.67 & 8 \\
\hline \multicolumn{8}{|c|}{ The role of expert systems as an access for Decision-making in sport institutions } \\
\hline $\begin{array}{l}\text { 8- Outputs of decisions support systems are used as determinants for the } \\
\text { inputs of the ES knowledge base }\end{array}$ & $\mathbf{0}$ & 19 & 31 & 131 & 29.31 & 87.33 & 12 \\
\hline $\begin{array}{ll}\text { 9- Improving processes of decisions making ( strategic - tactical - } \\
\text { administrative ) in sport institutions }\end{array}$ & $\mathbf{0}$ & 6 & 44 & 144 & 68.31 & 96 & 6 \\
\hline $\begin{array}{l}\text { 10- Providing more alternatives for the decision maker in the process of } \\
\text { solving the problem that make the decisions more consistent }\end{array}$ & $\mathbf{0}$ & 24 & 26 & 126 & 25.11 & 84 & 13 \\
\hline $\begin{array}{l}\text { 11- Taking the decision with the level of the expert specialized in all stages of } \\
\text { decision making process }\end{array}$ & $\mathbf{0}$ & 7 & 43 & 143 & 63.87 & 95.33 & 7 \\
\hline $\begin{array}{l}\text { 12- Getting consultant or the result quickly allowing the evaluation of the } \\
\text { decision results }\end{array}$ & $\mathbf{0}$ & 12 & 38 & 138 & 45.27 & 92 & 9 \\
\hline
\end{tabular}




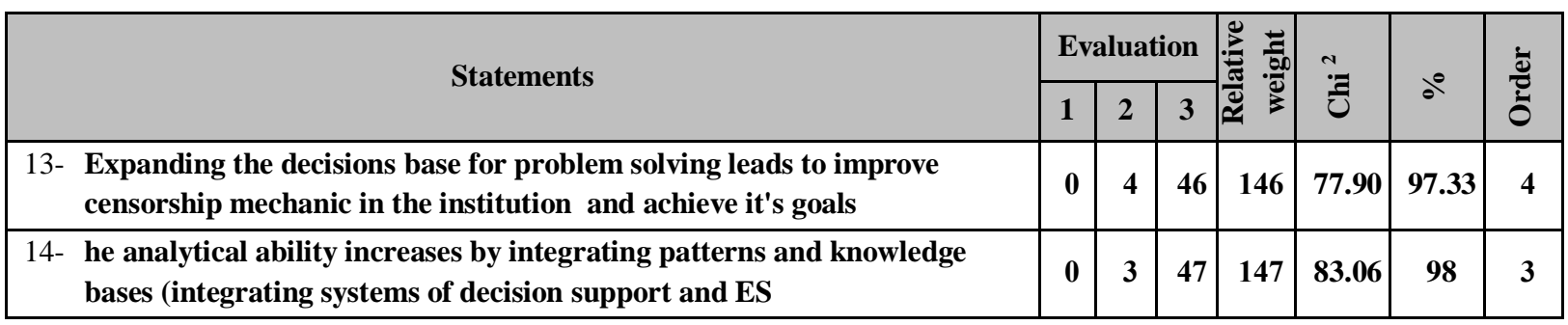

\section{The tabulated $\mathrm{Chi}^{2}$ at freedom degree (2) and significance level $(0.05)=5.99$}

It is shown from table (8) that there are significant differences between the real and expected opinions for the study sample in all statements of the fourth axis where the calculated chi $^{2}$ values range between "84: 100" and they are all statistically significant on behalf of the maximum importance of the statements. The relative weight of the sample opinions ranged between "84: 100"

Both the researchers attribute this for considering the ES represent the applied pattern of the knowledge engineering for its high ability on producing innovative ideas, the practical solutions for the complicated problems and devising results according to the available data with documenting the knowledge and the human experience and supporting structured and non-structured decisions making since decision making relies on several standards and consequently searching for problems solutions during applying this knowledge derived from accumulating experiences and its ability to overcome obstacles resulting from littleness of experts and high cost of their functioning and others, it is an inventive methodology deriving it's ability from knowledge base ( the basic component of the system ) and it's competent use is reflected on decisions and management performance of sport institutions and implementing its strategic goals where leadership system supervises and modifies what is accomplished on the part of the administrative system. The role of information system is represented in coordinating between the two systems. This accords with the opinion of Bhargava; power\&Sun (2007) (14), Russell \&others (2010) (19)

Both the researchers show the role of decisions support system in sport institutions according to the stages of its preparation as follows:

1- The stage of inquiry: the sub systems of decision support store huge amounts of information on the data base that can be beneficial for the decision maker and help him to recognize problems and detect solutions opportunities through its ability on building patterns and analyzing them where ES help in the process of categorizing the problem through its determination, categorization and displaying the extent of its danger.

2- The stage of designing the pattern: systems of decision support recognize the possible alternatives for solving the problem and the standards of preferring them and provide arithmetical patterns and the quantity and support them the ES by providing alternatives for solving the complicated problems and predicting the results of applying these alternatives. But systems of decision support are not considered an alternative of the manager but assisting him in decisions that can be programmed partially only and the great role of the manager in controlling and decisions making through his interaction, so system should be characterized with response flexibility for unexpected needs from information in addition to providing better controlling in terms of safety and procedures of security and peace and increasing the effectiveness of communication and coordination between organized units of sport institutions and reducing the cost of information , providing competitive benefits and the effectiveness in meeting user's needs.

3- The stage of research and selection: modern decisions depend upon the technicality of analysis and modeling for information and searching the ideal solutions. The result is an increase in the institution ability to confront changes (internal - external), raising technical, management and organization level inside sport institutions, the effectiveness rationalization the process of decisions making, increasing potentials and abilities of institutions in dealing with information and data bases, increasing speed, accuracy and privacy of information exchange between external units and destinations as considered an opening system.

4- The stage of application: decision implementation necessitates the process of persuading the participated an implemented part, the relation is direct between parts persuasion and the easiness of decision support system outputs.

Both the researcher see the evaluation of management support systems by comparing system outputs with the desired results and it's competency in a way achieving goals in the light of inputs and costs and it's quality by superiority of system performance as whole on sum parts constituting it and its response speed. The level of production and success in management depends on implementing some management functions (planning - organization controlling) and in its light the manger should make his decisions on condition the availability sufficient amount of accurate information with their different sources and categorizations. The previous mentioned accords with the opinions of Kamal Darwish \& Mohamed Hassanein (2004) (14),Srhoj\&Cavala (2010)(21), Wagner\&Najdawi ( 2003) ( 
23).Both the researchers summarize the role of ES in managing sport institutions in the following:

- (knowledge base): includes sum experiences in one field of sport management, including ( events base ) sum of data pertaining the problem (the research subject), as for (inference engine), it is a set of programs allowing search in knowledge base to find the suitable suggestions, raise the necessary complementary questions to solve the problem , diagnose and suggest solutions, consequently we might consider expert system as a mediator between the expert and the used and there are specific numbers of typical problems controlled by technicality of ES and they are problems can't solve with the $\mathrm{Al}$-Khwaizmi conventional technicality or they were solved but not the ideal solution

- Analyzing the problems and taking the decisions after accurate diagnosis and selecting the ideal solution in the light of data deficiency, developed cases, non-fixed such as crisis , categorizing tasks and allocating resources, selecting the suitable information, prediction, correcting errors, design and process patterns, bio technology and strategic planning .

- Accomplishing difficult decisions with expert and objective levels by its emphasis on strategies of solving the problem of a specific field rather than the method of processing the conventional data. Selfknowledge is used in thinking about inference processes and justifying these results. It's application aspects are multiplied in sport management such as marketing, financial, insurances, information , statistics and modeling, translation, law, sport industries, managing the human resources, evaluating performance and training, work relations and other generalizations and privacy of sport management . This accords with the opinion Grzegorz , Domino (2011)(16) , Roguji ,Papic , Plestina (2006)(18), Bartlett (2006)(13),(2002)(20), Dezman \&Dizdar (2001)(15) .

- Export systems are directed towards analyzing problems and decisions support systems with its different levels as follows:

- Strategic decisions: that requires qualifications and competencies of the public management. They are non-structured decisions and related with institutions managers abilities and their management knowledge where they help them in general diagnosis of the institutions, selecting and evaluating the budget and taking marketing strategic decisions for the sport institutions.

- Tactical decisions: are making in a low level than the previous (intermediate management). These decisions serve the whole strategy of the institution and it is more structured compared with the strategic decisions and are characterized with frequency such as financial and administrative management in sport institutions.

- The practical (administrative) decisions of sport institutions and help in design and production by the computer, categorizing and planning the processes , installations and equipments, maintenance, supervising the performance, security and alarming system.

Both the researchers see the close relation between decisions support systems and ES as an access for decisions taking in sport institutions in the presence of more than one form to make use of knowledge by integrating the support system with the quantitative patterns, ES and others to help the user in selecting the pattern appropriate for solving the raised problem, supporting the processes of decision making in situations in which using arithmetical patterns and providing ES with the analytical ability for dealing with uncertainty cases .

The previous mentioned accords with opinions of Moustafa Habashy (2008)(9), Yasser Nousear (2005)(11), Gamal Galal (2002)(3), Russell\& others (2010)(19), Srhoj\& Cavala (2010)(21), Bai\& Chen (2008)(12) , Bhargava , Power \&Sun (2007)(14), Kim, Song \&Hong (2005)(17).

\section{Conclusions:}

In the light of discussing the study results, both the researchers found the following conclusions:

1- Egyptian sport institutions are not interest in modern tools for supporting the strategic decision where they have data base storing only historical information only so that the decision maker can return back to them in similar instances, as well as objection the existence of any form of ES in managing sport institutions or knowledge bases supported with experts to communicate knowledge and experience from the human to the computer and facilitate it's use by the decision Maker.

2- ES \& DSS are fundamental tools for changing inside sport institutions. Institution adoption for developing and renewing information systems became a pillar in which the institution strategy is built, and it's contribution in supporting the management functions (planning - organization - guidance - censorship , the process of decisions taking) whenever it was found inside the system, so it supports the processes ( production - marketing - funding - individuals management ) through providing information to select alternatives and suggest problems solutions by which the institution confronts 


\section{Recommendations:}

Based upon the results and conclusions of the study, both the researchers recommend the following:

1- Applying technicalities of ES and decision support systems for supporting the process of decisions making in sport institutions by reconsidering its organized structures and re- engineering it's processes that are appropriate with the developments in the field of information systems to treat risks and not certain during preference between alternatives as an investment project that has its technical and human use and publication potentials on the part of the user in the market.

2- Innovating " expert base " and managing with methods and systems meeting the emergent manager needs of information and can interact with the computer whether by (introducing new variables or conducting changes in suggesting a problem or a pattern or preparing a scenario for displaying suggested solutions for a problem or selecting the best solution and preparing special reports ) so the cost and risks reduce in the activities of sport institution by providing several competencies and experiences it is difficult to collect.

\section{References}

\section{Arabic references:}

1- Ahmed El Khateap \&Khaled Zeghan:Managing knowledge and information systems , House of scientific book, publication and distribution , Oman, 2009.

2- Gassem Hamead Zooeal : Constructing Expert system and management information bank by using integrated computer information bases, magazine of management and economy, no.98, Iraq ,2011.

3- Gamal Mohamed Galal: Obstacles of using computer and information systems in sport clubs at Arab Republic of Egypt, unpublished master thesis, faculty of physical education for men, Cairo, Helwan University, 2002.

4- Hassan Ahmed El Shafey: Contemporary applications of management in physical education and sport, Alexandria, Dar El Wafae for press and publication, Alexandria, 2010.

5- Afaf Abdel Menaen Darwish : Technology of managing sport institutions ( information - decision making, communication, documentation, follow up , censorship , treatments ) Menshat El Maaref , Alexandria , 2009 .
6- Alaa Abdel Razek ElSalmy:Systems of information and artificial intelligence ,El Manahg house for publication and distribution , Oman , Jordan , 1999.

7- Kamal El Din Darwish,Mohamed Sobhy Hassanein : Encyclopedia of sport management directions in the beginning of the new century, the third volume (marketing,modern communication, dynamics of the human performance ) in managing sport works , Dar El Feker Al Araby, Cairo, 2004 .

8- Mohamed Abdel Aziz Slama , Samir Abdel Hamid Aly : A modern perspective in sport management , Mahy for publication and distribution, Alexandria , 2007.

9- Moustafa Hassan Habashy : A suggested pattern for managing information systems in some sport clubs at Arab Republic of Egypt , unpublished doctoral thesis , faculty of physical education for boys , Alexandria university ,2008 .

10- Nabil Mohamed Morsy, Asrar Deab : Systems of management information, House of the new university , Alexandria university, 2008

11- Yasser Khaleal,Hussein Nosear : A suggested system for electronic management in sport clubs, faculty of physical education for boys , Cairo, Helwan university , 2005 .

\section{Foreign references:}

12- Bai,S.M;\&Chen,S.M. Evaluating students learning achievement using fuzzy membership functions and fuzzy rules. Expert systems with applications, 34, 399410, 2008

13- Bartlett, R. Artificial intelligence in sports biomechanics: New dawn or false hope? Journal of sports science and medicine, 5,474- 479, 2006.

14- Bhargava, H. K; Power, D.J\& Sun, D: Progress in web - based decision support technologies. Decisions Support Systems, 43, 1083 - 1083. 2007.

15- Dezman , B; Trninc, S.\& Dizdar , D.: Models of expert systems and decision making systems for efficient assessment of potential and actual quality of basketball players , Kinesiology ,33 (2 ) , 207215,2001

16- Grzegorz Domino : Inspection of applications of expert systems in sport, Journal of health promotion 
and recreation, Faculty of physical education , university of Rzeszow ( Poland ), 11- 16, 2011 .

17- Kim, W;Song,Y.U\& Hong , J. S: Web enabled expert systems using hyperlink based inference. Expert systems with applications, Issues 28, 79- 91, 2005.

18- Rogulj, N;Papic,V;\&Plestina, $\mathbf{V}$ : Development of the expert system for sport talents detection. WSEAS transactions on information science \& applications, issue 3, volume 9, 1752-1755, 2006.

19- Shim, J. P; Warkentin, M.; Courtney, J. F; Power, D. J., Sharda, R.\&Carlsson , C: past , present , and future of decision support technology . Decision Support Systems, volume 33(2), 111-126(16), 2006.
20- Srhoj, Lj., Mihaljevic,D.\&Cavala, M: Application of expert systems for talent scounting in dancing. Acta Kinesiology 4(1), 109 - 113, 2012.

21- Simic, G.\&Devedzic, V: Building an intelligent system using modern internet technologies . Expert systems with applications, Issue 25, 231- 246, 2003.

22- Wagner, W. P.; Chung, Q. B\& Najdawi, M. K: The impact of problem domains and knowledge acquisition techniques: a content analysis of P/OM expert system case studies. Expert systems with applications , 24,7986,2008

23- Russell Hoye \& others: Sport management principles and applications, Linacre House, Jordan Hill, Oxford ox28DP. 30 Corporate Drives, Suite 400, Burlington, MA01803.2012. 